\title{
The Diurnal Cycle of Convective Activity over South Asia as Diagnosed from METEOSAT-5 and TRMM Data
}

\author{
Bhuwan Chandra Bhatt ${ }^{1, *}$, Tieh-Yong Koh ${ }^{1,2}$, Munehisa Yamamoto ${ }^{3}$, and Kenji Nakamura ${ }^{4}$ \\ ${ }^{1}$ Temasek Laboratories, Nanyang Technological University, Singapore \\ ${ }^{2}$ School of Physical and Mathematical Sciences, Nanyang Technological University, Singapore \\ ${ }^{3}$ Center for Environmental Remote Sensing, Chiba University, Japan \\ ${ }^{4}$ Hydrospheric Atmospheric Research Center, Nagoya University, Japan
}

Received 28 September 2009, accepted 4 February 2010

\begin{abstract}
Cloud and precipitation data from satellites were used to characterize the climatological diurnal cycle of convective activity over South Asia. Spatial and temporal variability were investigated using three hourly blackbody brightness temperature $\left(\mathrm{T}_{\mathrm{BB}}\right)$ data from the METEOSAT-5 during March-April-May (pre-monsoon) and June-July-August (summer monsoon) of 1999 - 2000. We focused on three regions over South Asia: region A in the Himalayas, region B in north India and region C in the Bay of Bengal (BOB). The cloud cluster (CC) technique was used first to detect deep convection over north India during the summer monsoon when deep convection was less frequent; cloud cover frequency (CCF) was used to diagnose convection of a moderate depth. $\mathrm{T}_{\mathrm{BB}}$ thresholds of 219 and $235 \mathrm{~K}$ were used in the $\mathrm{CC}$ and CCF methods, respectively. Ten years of Tropical Rainfall Measuring Mission (TRMM) rainfall product (3B42) was analyzed as well to check the METEOSAT-5 findings.

The diurnal cycle varies greatly with location. In the pre-monsoon season, there were many CC over region B especially during the late afternoon hours. But deep convective activity was weaker during the summer monsoon season as convection mostly reached the mid-troposphere only. Bimodal diurnal cycle in CC occurrence was noted in the region A during summer monsoon, with the morning mode having more of the larger clusters than the afternoon mode. The afternoon mode appears to be suppressed in the presence of strong ambient wind shear. The life cycle of cloud clusters during summer monsoon is also worthy of note: statistically speaking, there is a gradual delay in the preferred time of initiation, attainment of maximum area and dissipation as one progresses northward from regions $\mathrm{C}$ through $\mathrm{B}$ to A. More clusters survive for longer than 3 hours in region $\mathrm{C}$ as compared to the other two regions.
\end{abstract}

Key words: Convective activity, Diurnal variation, Climatology, South Asia

Citation: Bhatt, B. C., T. Y. Koh, M. Yamamoto, and K. Nakamura, 2010: The diurnal cycle of convective activity over South Asia as diagnosed from METEOSAT-5 and TRMM data. Terr. Atmos. Ocean. Sci., 21, 841-854, doi: 10.3319/TAO.2010.02.04.01(A)

\section{INTRODUCTION}

The terrain of South Asia constitutes a highland-lowland system (Fig. 1 upper panel) that influences synoptic and mesoscale weather. The Himalayas and Tibetan plateau is a major highland feature, with steep slopes flanking the southern edge of the Himalayas. In contrast, north India is relatively low-lying. Widespread cloud and precipitation before and during the summer monsoon in this sub-continent has long been recognized (Webster and Yang

\footnotetext{
* Corresponding author

E-mail:BCBHATT@ntu.edu.sg
}

1992; Goswami 2000; Webster et al. 2002). The summer monsoon precipitation is well-organized in space with the heaviest rainfall over regions in the Bay of Bengal (BOB), Arabian Sea, and southern slopes of the Himalayas (Adler et al. 2000; Xie et al. 2006). The frequency of convection is modulated by a variety of phenomena including monsoon depressions, intraseasonal active-break phases and the local diurnal circulations such as land-sea breezes and mountainvalley winds.

Changes in deep convective activity on the diurnal time scale have been observed in many places around the globe 
(a)

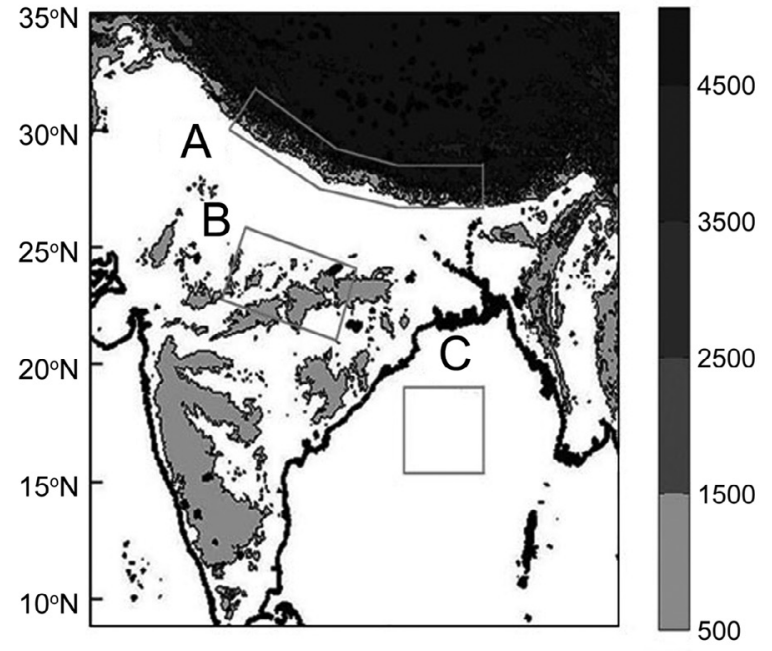

(b)

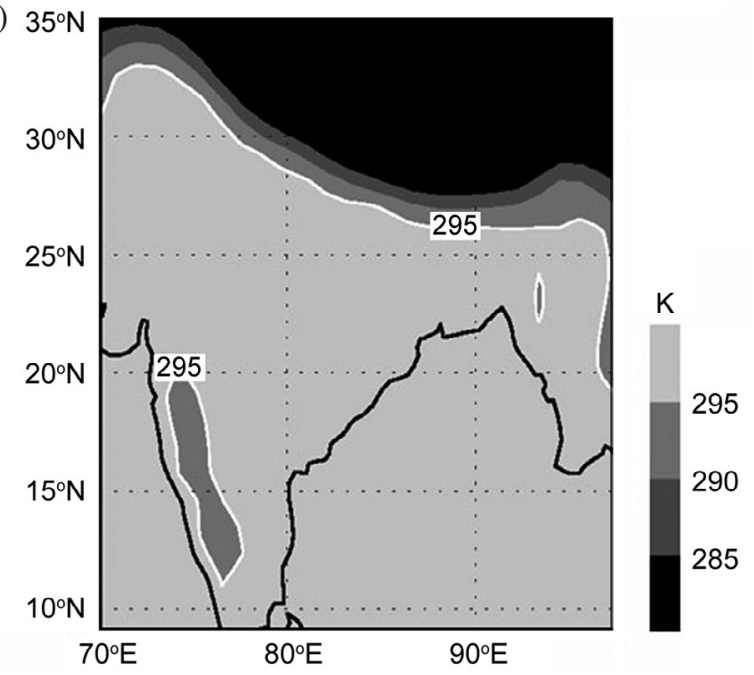

Fig. 1. (a) shows terrain height (unit: $\mathrm{m}$ ) over South Asia. The three regions used to study cloud diurnal variations are: region A, B, and C. (b) shows the average land and sea surface temperature, i.e., "skin temperature," at 0600 LT (0000 UTC) during JJA 1994 - 2000 computed from ECMWF 40-year reanalysis monthly mean data at $1.125^{\circ} \times 1.125^{\circ}$ grid resolution. The $295 \mathrm{~K}$ contour (white) is also drawn.

(e.g., Yu et al. 2007). Among all observation platforms, satellites provide the widest geographical coverage. In particular, geostationary satellites provide the rapid temporal update cycle needed to capture the growth and decay of precipitating cloud systems on a scale of several kilometers and are suitable for sampling the diurnal cycle. Several observational studies (Fritsch et al. 1986; Hilgendorf and Johnson 1998) have shown that diurnal convection is organized in Mesoscale Convective Systems (MCSs) and produce heavy precipitation. Laing and Fritsch (1997) described MCSs development and convective activity at a global scale using International Satellite Cloud Climatology Project (ISCCP) data.

Diurnal variability and underlying mechanisms over the global tropics was discussed by Yang and Smith (2006) using Tropical Rainfall Measuring Mission (TRMM) satellite rainfall data. They suggested that heavy rainfall areas exhibit strong diurnal variations. There are also notable regional studies using satellite cloud data: e.g., in East Asia (e.g., Wang et al. 2004), the Western Pacific warm pool (e.g., Mapes and Houze 1993), and maritime continent (e.g., Short and Wallace 1980; Williams and Houze 1987; Kondo et al. 2006).

As for data analysis techniques, for instance, Williams and Houze (1987) investigated cloud systems using a cloud-tracking methodology that is also employed in this paper. Their technique was based on a minimum overlapping area between MCSs in successive images. Machado et al. (1998) concluded that area overlap technique works well for data having a 3-hour temporal resolution as well as for large convective systems. Kondo et al. (2006) was one of the first cloud-tracking studies that made combined use of the Geostationary Meteorological Satellite (GMS) cloud data and the Tropical Rainfall Measuring Mission (TRMM) precipitation data over the maritime continent to elucidate on evolution stages of cloud systems.

Many studies focused on characterizing convection over South Asia; a few of them relevant to this work are briefly described next. Kodama et al. (2005) reported maximum lightning activity over the east coast and north part of India during the pre-monsoon season. In this season, the most intense convection north of $28^{\circ} \mathrm{N}$ latitude was noted over the northwestern part of South Asia (Zipser et al. 2006). Over the northeastern part of South Asia, deep intense convection in the form of isolated cells or as part of large MCSs was noted by Houze et al. (2007).

During the summer monsoon season, most convective systems were of cumulus scale over the Himalayas but of mesoscale elsewhere in South Asia (Hirose and Nakamura 2005). In the Himalayas, bimodal diurnal cycle of rainfall has been reported from limited ground-based and satellite observations (e.g., Ueno et al. 2001; Barros and Lang 2003; Bhatt and Nakamura 2006). South of the Himalayas, a single afternoon convective maximum is observed (e.g., Gambheer and Bhat 2001; Nesbitt and Zipser 2003; Roy and Balling 2006). In fact, Krishnamurti and Kishtawal (2000) noted that over north India, the diurnal circulation extends to almost continental scale. They found that the diurnal westward movement of MCSs in north India is favored by the existence of the Tibetan high and the tropical easterly jet. The origin of this westward movement lies over the BOB where Liu et al. (2008) reported distinctly multiscale convective organization. The MCSs there were found to be embedded in synoptic-scale monsoon depressions (Houze and Churchill 1987; Johnson 2009). Over the northwest side of BOB, Zuidema (2003) documented a high degree of con- 
vective activity with morning maximum in cloudiness in the summer monsoon season, land-sea contrast being important for the genesis of convection.

The BOB summer monsoon depressions usually move northward or northwestward accompanied by the onshore transport of moist air (Houze and Churchill 1987). The most relevant features of these depressions are enhanced winds, blocked by the Himalayas and substantial convective organization (Barros and Lang 2003). The associated rainfall is distributed across three regional maxima centered separately in the BOB, north India and the southern slopes of the Himalayas (see Fig. 1b in Xie et al. 2006)(Note that there are higher rainfall maxima further west, i.e., offshore of the Western Ghats, and further east, i.e., offshore of the Myanmar coast). The importance of the diurnal variability of convection in these heavy-rainfall centers was emphasized by Xie et al. (2006). Heavy rainfall regions are also noted to exhibit strong diurnal variations in a global study by Yang and Smith (2006).

The diurnal variability over the centers of heavy rainfall in the BOB, north India and the Himalayas has not been sufficiently researched and deserve further attention. Based on the TRMM observations reported by Xie et al. (2006), three convective centers of interest are identified for this work: region A in the Himalayas; region B in north India and region $\mathrm{C}$ in the $\mathrm{BOB}$ to examine fine-scale variations of convective activity. The upper panel of Fig. 1 shows the three regions selected.

The objective of this study is to characterize the climatological diurnal cycle of moderate and deep convection over the three previously identified South Asian centers of heavy rainfall in the pre-monsoon and especially in the summer monsoon seasons. We use high spatial resolution infrared (IR) data denoting cloud fields from METEOSAT-5. As much work has already been done for certain aspects of the diurnal cycle in South Asia, this study also aims to demonstrate some of the more notable findings in the literature using the more recent METEOSAT-5 dataset. For South Asia, METEOSAT- 5 centered at $63^{\circ} \mathrm{E}$ provides the best coverage among openly accessible datasets. Because we only had two years of METEOSAT data, we also performed a simple validation of METEOSAT-5 results with TRMM data from over ten years.

The paper is arranged in the following manner: section 2 describes the data and methods; sections 3 and 4 present results from METEOSAT-5 and TRMM, respectively; section 5 represents discussion; and section 6 is the summary of our key results.

\section{DATA AND METHOD}

Two sets of satellite data were used. One was the TRMM rain product (3B42) available on $0.25^{\circ} \times 0.25^{\circ}$ grid with a temporal resolution of 3 hours from 1999 to 2008 .
This product is from multiple satellite microwave and infrared measurements (Huffman et al. 2007). The other was METEOSAT-5 IR blackbody brightness temperature $\left(\mathrm{T}_{\mathrm{BB}}\right)$ data available with a spatial resolution of $5 \mathrm{~km}$ and temporal resolution up to 1 hour for 1999 and 2000 but data at hand was limited to 0000, 0300, 0600, 0900, 1200, 1500, 1800, and 2100 Local Times (LT) to be comparable with the TRMM dataset. Local times used here are Universal Time Coordinate (UTC) +6 hours. TRMM satellite is not in a sun-synchronous orbit. Long-term data accumulation is necessary to reconstruct the diurnal cycle for a fixed region on earth. In contrast, METEOSAT-5 is in geostationary orbit and so sampling is homogeneous. The chosen 3-hourly temporal resolution provides 8 data points over one day and is reasonably good for investigating the diurnal cycle. Phenomena at higher temporal resolution cannot be studied with the given data. Twelve months of data from both datasets were divided into two seasons: pre-monsoon season for March, April and May (MAM); and summer monsoon season for June, July and August (JJA).

Two methods were used to detect cloudiness. One utilized the cloud cluster (CC) technique while the other computed cloud cover frequency (CCF). In the $\mathrm{CC}$ technique, deep convective clouds were detected as patches of very low $\mathrm{T}_{\mathrm{BB}}$. A CC was defined as a contiguous area larger than $2000 \mathrm{~km}^{2}$ and with a $\mathrm{T}_{\mathrm{BB}}$ lower than $219 \mathrm{~K}$. The cold cloud area threshold of $2000 \mathrm{~km}^{2}$ is comparable with those used in Kondo et al. (2006) and Lensky and Rosenfeld (1997). Bigger thresholds have been used in the literature such as when the tracking methodology required internal structures of cloud systems to be resolved: e.g., about $30000 \mathrm{~km}^{2}$ (or effective radius of $100 \mathrm{~km}$ ) in Machado et al. (1998); or when larger-scale convective organization is investigated: e.g., William and Houze (1987) used $30000 \mathrm{~km}^{2}$ as a threshold to examine the influence of monsoon surges on larger cloud clusters. The cloud tracking procedure we adopted was similar to the one described by Williams and Houze (1987). The technique for tracking a CC from one time to the next assumes that $\mathrm{CC}$ at a later time corresponds to those at an earlier time if their positions overlap sufficiently. There is no restriction on the shape of the system. A "time cluster" (TC) was defined as a temporal set of CC where the area of overlap between two CC in consecutive satellite images exceeds $50 \%$ of the area of union. TCs which touch a boundary of the analysis region at any time are not considered in our work.

To detect convective clouds using the CCF technique, it was assumed that a cloudy sky is not only cooler but also has more heterogeneous distribution of $\mathrm{T}_{\mathrm{BB}}$ than a clear sky. Heterogeneity at a pixel was estimated by computing the standard deviation (std) within the neighborhood of the pixel (i.e., $3 \times 3$ pixels inclusive of the central pixel itself) along the lines of the classical spatial coherence technique (Roca et al. 2002). Thus, higher spatial resolution is neces- 
sary for this technique than for the $\mathrm{CC}$ technique. A pixel was classified as cloudy if $\mathrm{T}_{\mathrm{BB}}$ is less than $295 \mathrm{~K}$ and std is greater than $0.5 \mathrm{~K}$ in the neighborhood of the pixel. The cutoff of $295 \mathrm{~K}$ was applied as a filter to remove (inasmuch as possible) land surface contributions during clear-sky situations when computing the std. The choice of $295 \mathrm{~K}$ may not be conventional, but it is not unique in the literature: e.g., Fu et al. (2006) also defined a relatively high $\mathrm{T}_{\mathrm{BB}}$ cut-off of $300 \mathrm{~K}$ for cloudy sky conditions over east China. The crux is that for the monsoon season, even nighttime land surface temperature over the interior of India (including region B) is higher than $295 \mathrm{~K}$, as evidenced by the lower panel in Fig. 1 which shows the average land and sea surface temperature at 0600 LT during JJA 1994 - 2000 from the European Centre for Medium-Range Weather Forecasts (ECMWF) 40-year reanalysis dataset (Uppala et al. 2005). Note that the CCF technique was applied only to the summer monsoon season in this paper.

After detecting pixel is determined as cloudy by the above criterion, a threshold of $235 \mathrm{~K}$ was used to distinguish convection of (at least) moderate depth (i.e., cloud tops reaching into the mid-troposphere) from shallow convection. $\mathrm{T}_{\mathrm{BB}}<235 \mathrm{~K}$ usually indicates the occurrence of rain, according to Arkin and Meisner (1987) who developed the Geostationary Operational Environmental Satellite (GOES) Precipitation Index (GPI). Other thresholds of $\mathrm{T}_{\mathrm{BB}}$ have also been defined before in the literature for clouds associated with precipitation (e.g., Williams and Houze 1987; Machado et al. 1998; Roca et al. 2002). Finally, CCF was computed in $10 \mathrm{~km} \times 10 \mathrm{~km}$ grid boxes by taking the ratio of the frequency of occurrence of convection of at least moderate depth $\left(\mathrm{T}_{\mathrm{BB}}<235 \mathrm{~K}\right)$ to the frequency of occurrence of cloudiness $\left(\mathrm{T}_{\mathrm{BB}}<295 \mathrm{~K}\right.$ and std $>0.5 \mathrm{~K}$ ) in each box. Thus, the CCF defined here is the fractional contribution of convection of at least moderate depth to cloudiness. Clearly, this definition of $\mathrm{CCF}$ is not applicable for highlands such as region A where surface temperature is colder than $295 \mathrm{~K}$.

Apart from satellite datasets, $500 \mathrm{hPa}$-wind data from the National Center for Environmental Prediction (NCEP) and National Center for Atmospheric Research (NCAR) Re-Analysis (NNRA) was used to provide the synoptic wind information (Kanamitsu et al. 2002).

\section{METEOSAT-5 RESULTS}

As only 2 years of Meteosat- 5 data was used in this study, it is important to first check that those two years are not exceptional with regard to inter-annual climatic variations in the region. Although during 1999/2000, global tropical circulations were under the influence of La Niña (Anyamba et al. 2002), normal rainfall activity was noted during 1999 and 2000 monsoons over India and Nepal (Shrestha 2000; Lang and Barros 2002). Rahman and Simon (2006) did not find significant differences in 1999 and 2000 monsoons over east Arabian Sea, while Bhatt and Nakamura (2005) observed similar spatial pattern of diurnal cycle of rainfall for these two years over South Asia (cf. their Fig. 4 in Bhatt and Nakamura 2005). So, it is not unreasonable to combine these two years for a composite analysis of cloudiness.

\subsection{Pre-Monsoon}

The space-time variability of deep convective clouds during the pre-monsoon will be described first. We examined a real representation of the diurnal cycle of cloudiness without considering each CC's life span over South Asia in the three regions. Figure 2a shows the diurnal variation of the normalized number of $\mathrm{CC}$ over a day for the pre-monsoon season. The average number of $\mathrm{CC}$ in every 3 -hour interval in local time has been normalized by the respective total number of $\mathrm{CC}$ in a day for each region so that the relative variation stands out. The peak occurrence of $\mathrm{CC}$ over region $\mathrm{B}$ and region $\mathrm{A}$ is in the mid-afternoon (1500 LT). This midafternoon peak is similar to that from cloud data analysis by Gambheer and Bhat (2001) although our study is centered on a smaller study area. This result also concurred with Bhatt and Nakamura (2006) that reported afternoon rainfall over the Himalayas. On the other hand, in region $\mathrm{C}$, the

(a)

Fraction

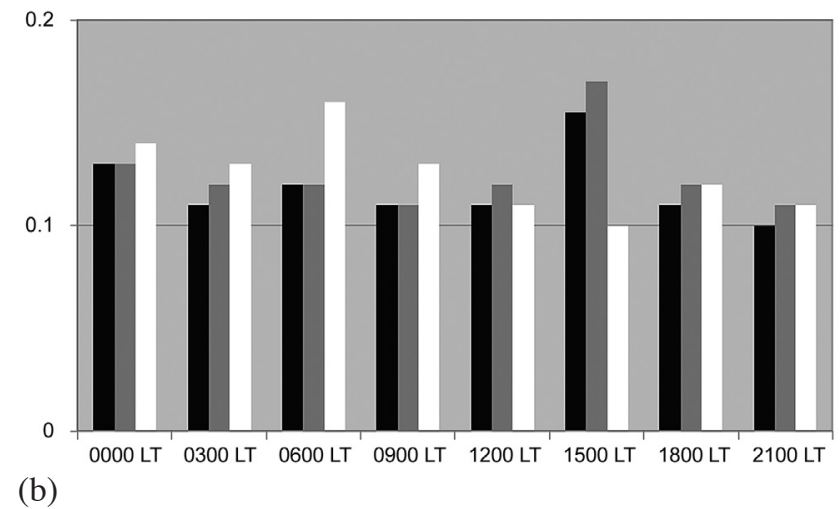

(b)

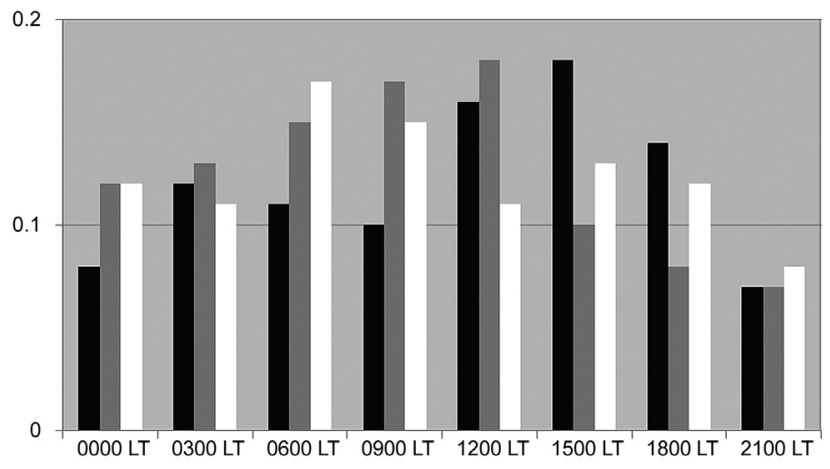

Fig. 2. Diurnal variation of the number of $\mathrm{CC}$ normalized by the total number of CC over a day for each region during (a) MAM 1999 - 2000 and during (b) JJA 1999 - 2000. The black, gray and white bars denote results for the regions $\mathrm{A}, \mathrm{B}$, and $\mathrm{C}$ respectively. 
maximum occurs in the early morning (0600 LT). Thus, the phase of the diurnal cycle differs greatly between land and sea. Note that in all three regions, small secondary peaks are seen at $0000 \mathrm{LT}$. Previous studies on diurnal variations (e.g., Bhatt and Nakamura 2006) didn't find such small secondary peaks in convective activity during the pre-monsoon season. This surprising finding is left for future study.

Next we examined the spatial distribution of CC during the pre-monsoon season. The spatial distribution of the number of $\mathrm{CC}$ in $0.5^{\circ} \times 0.5^{\circ}$ grid boxes over the diurnal cycle is shown in Fig. 3. The preferred region of CC occurrence is region $B$ (cf. the ellipse in Fig. 3f). The enhanced $\mathrm{CC}$ distribution over north India including region B is nearly oriented in a NE-SW direction. Minoura et al. (2003) noted enhanced static instability around the same area during premonsoon, Yamane and Hayashi (2006) also suggested large static instability and vertical wind shear over the dry-line region in north India. Hence, CC distribution could be related to static instability in the lower atmosphere. Note that there are also more $\mathrm{CC}$ over region $\mathrm{A}$ corresponding to the two peaks in the diurnal cycle (cf. elongated ellipses in Figs. 3a and $\mathrm{f}$ ).

\subsection{Summer Monsoon}

It is well-known that the summer monsoon in South Asia is characterized by widespread cloudiness (Webster and Yang 1992; Webster et al. 2002; Houze et al. 2007). Figure $2 \mathrm{~b}$ shows the diurnal variation of the normalized number of CC over a day for the summer monsoon season. The peak appears earlier in this season at $1200 \mathrm{LT}$ over region $\mathrm{B}$, while the peak of region A remains at $1500 \mathrm{LT}$. The shift in the time of maximum convective activity from early afternoon in region B to late afternoon over region A may suggest a northward migration of deeply convecting MCSs. The afternoon rainfall maximum over the Indian subcontinent (inclusive of region B) has been noted by Roy and Balling (2006). Afternoon convective activity over the Nepalese Himalayas (inclusive of region A) has been discussed in e.g., Ueno et al. (2001), Kurosaki and Kimura (2002), and Barros and Lang (2003). It is remarkable that peak convective activity occurs at $0600 \mathrm{LT}$ for region $\mathrm{C}$ during both the summer monsoon and the pre-monsoon. These results are in agreement with diurnal cycle studies by Ohsawa et al. (2001), Yamamoto et al. (2008) and Zuidema (2003) over the BOB region, though Zuidema (2003) noted that some convective cloud clusters do move southward from the BOB.

The spatial distribution of $\mathrm{CC}$ during the summer monsoon is shown in Fig. 4. In general, deep convective activity is weak during the summer monsoon and is centered over northwestern India. Over region B, late afternoon deep convection that is so prominent during the pre-monsoon is sparse during the summer monsoon (cf. ellipses in Figs. $3 \mathrm{f}$ and $4 \mathrm{f})$. This notable result is in agreement with the shift in peak activity from 1500 to $1200 \mathrm{LT}$ from pre-monsoon to monsoon season in Figs. 2a and b.

\subsubsection{Convection of Moderate Depth}

To investigate convection of moderate depth during the summer monsoon, the CCF was computed with high-resolution data at $0.1^{\circ} \times 0.1^{\circ}$. Figure 5 shows the diurnal cycle of the horizontal distribution of the $\mathrm{CCF}$ during the summer
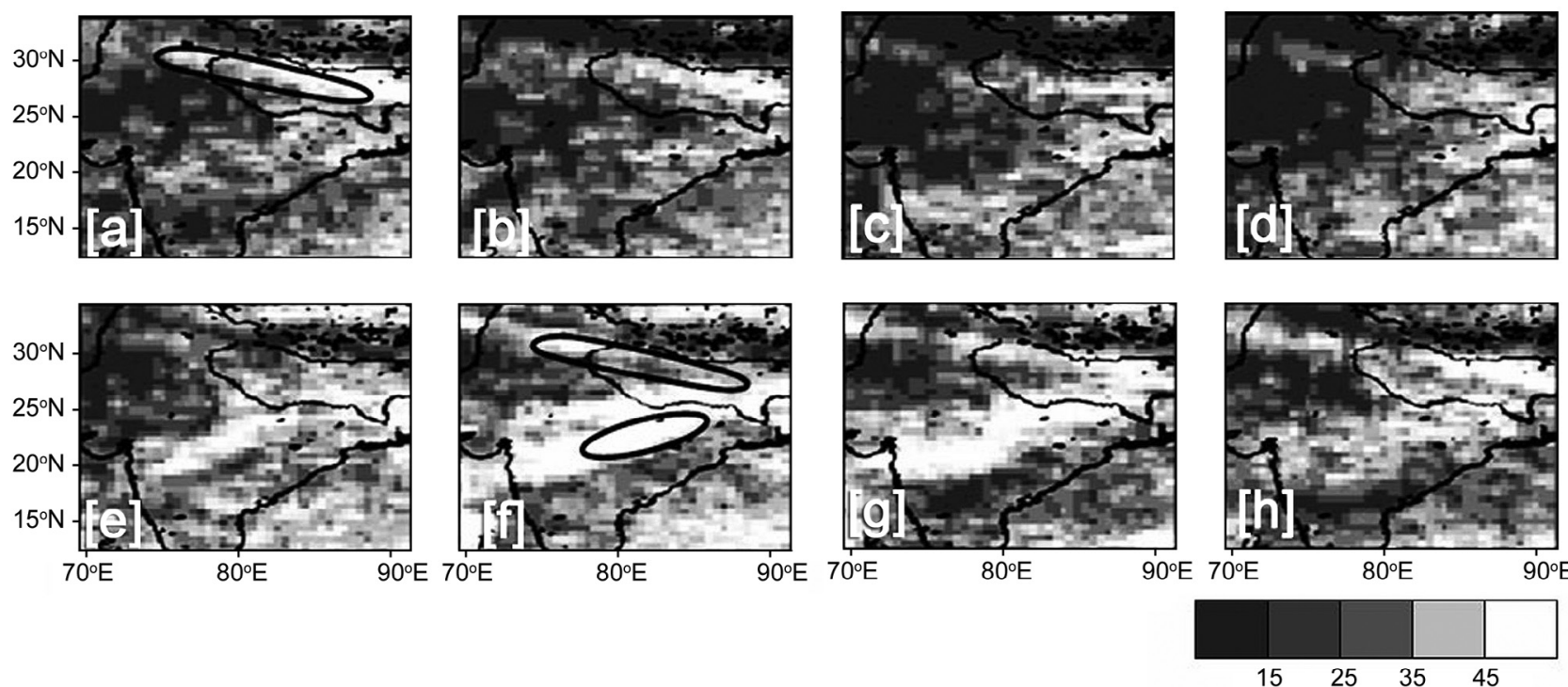

Fig. 3. Diurnal and spatial distribution of the number of CC in $0.5^{\circ} \times 0.5^{\circ}$ grid boxes during MAM 1999 - 2000. Panels (a), (b), (c), (d), (e), (f), (g) and $(\mathrm{h})$ correspond to $0000,0300,0600,0900,1200,1500,1800$ and $2100 \mathrm{LT}$ respectively. In panels (a) and (f), the elongated ellipses highlight the convection over region A. Another ellipse in panel (f) shows convection over region B. 

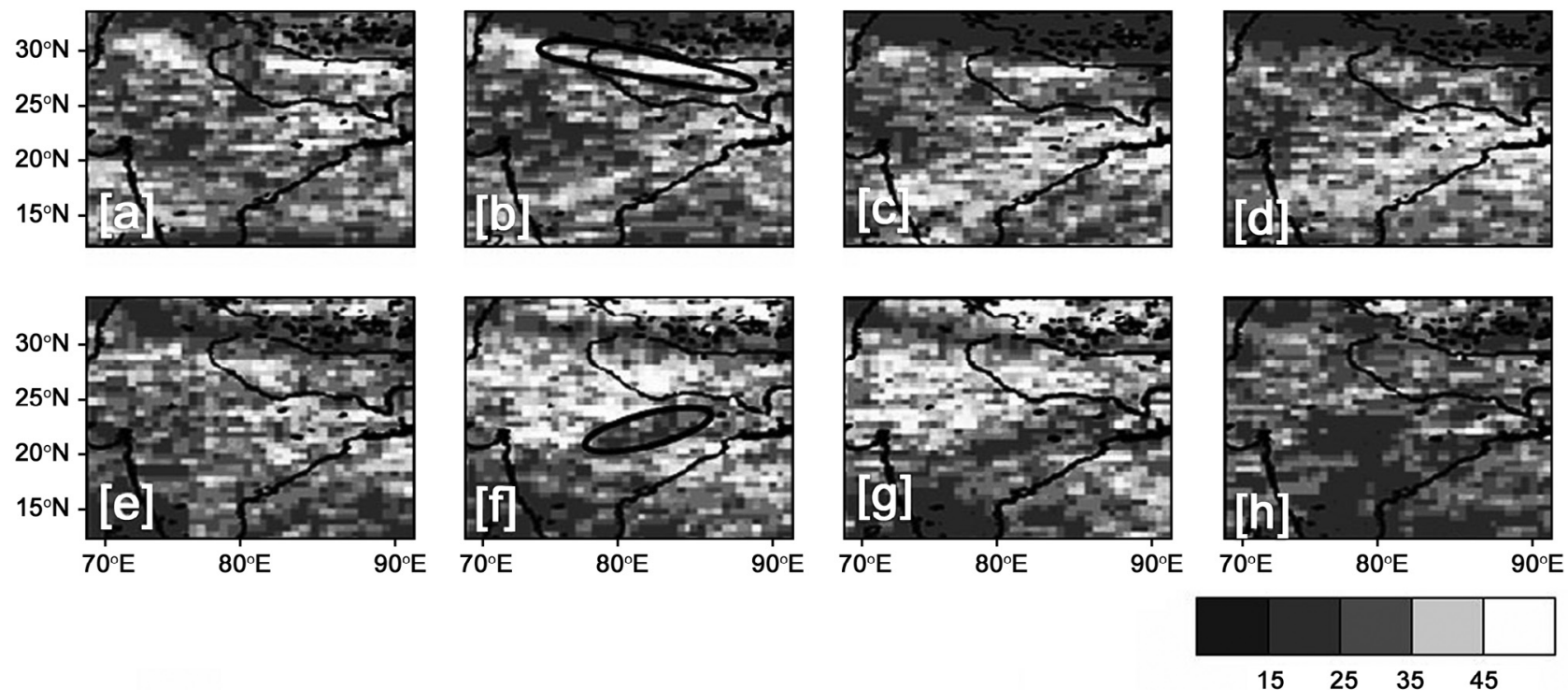

Fig. 4. Same as Fig. 3 but for JJA 1999 - 2000. In panel (b), the elongated ellipse highlights the early morning convection over the region A. In panel (f), the ellipse highlights diminished the late afternoon deep convection over region B.
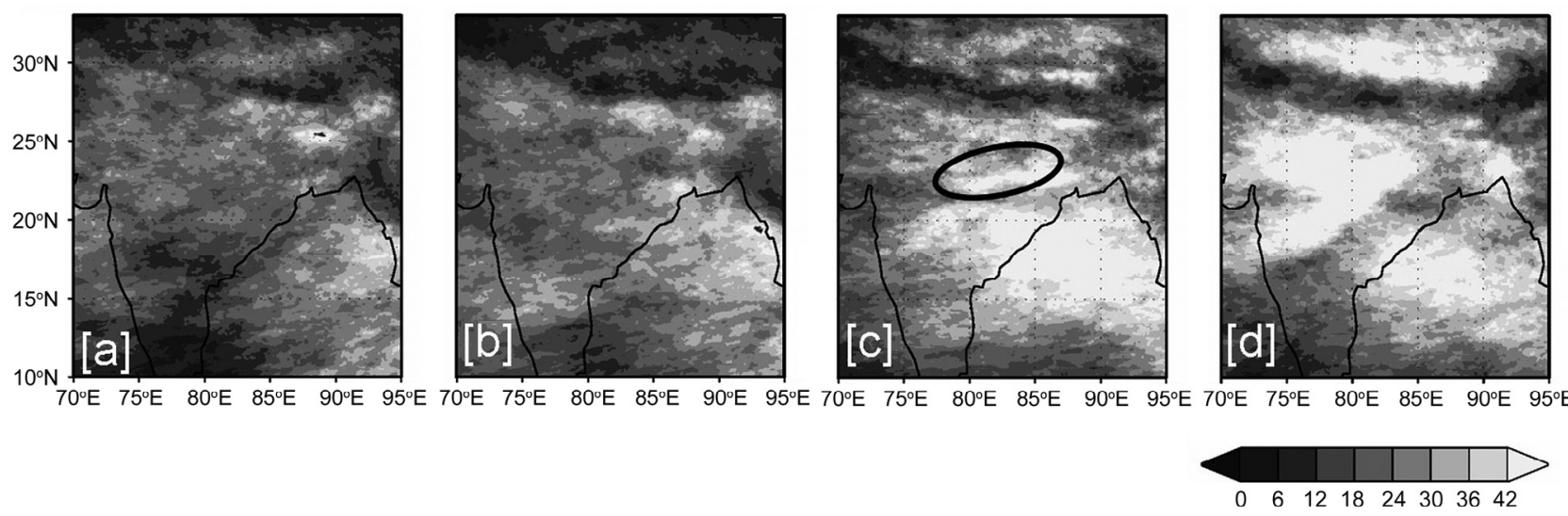

Fig. 5. Cloud cover frequency (\%) in $0.1^{\circ} \times 0.1^{\circ}$ grid boxes during JJA $1999-2000$ over South Asia. Panels (a), (b), (c) and (d) correspond to 0300 , 0600, 1500, and 1800 LT respectively. In panel (c), the ellipse highlights the presence of convection of moderate depth over region B during late afternoon (cf. Fig. 4f).

monsoon season. There is high a CCF over region B especially in the late afternoon (cf. ellipse in Fig. 5c), despite the sparseness of deep convection in that region noted earlier. This denotes widespread convection of moderate depth.

\subsubsection{Bimodal Diurnal Cycle}

Early morning convection was noted over region $\mathrm{A}$ in the distribution of CC (elongated ellipse in Fig. 4b). Analysis of cloud and rainfall data by Ohsawa et al. (2001) and Barros and Lang (2003) also revealed a similar diurnal cycle in the summer monsoon season.

Two distinct peaks of deep convective activity are seen over region A in Fig. 2b: a primary peak at 1500 LT (midafternoon) and a secondary peak at $0300 \mathrm{LT}$ (pre-dawn).
This bimodality is much stronger than was seen during premonsoon in Fig. 2a. Deep convection over the Himalayas during pre-dawn is reminiscent of that observed over the western United States (Wallace 1975; Carbone et al. 2002) and over Southeast Asia (Ohsawa et al. 2001). To further investigate, the day is partitioned into two parts: before noon (0000 - 1200 LT) and afternoon (1200 - 2400 LT).

Figure 6a shows the distributions of the normalized number of CC with the area of CC in JJA 1999 - 2000. Normalization was carried out over the total number of $\mathrm{CC}$ regardless of area in a day. Most CC have area between 2000 and $5000 \mathrm{~km}^{2}$, but secondary maxima in the distributions are visible around $35000-40000 \mathrm{~km}^{2}$.

Figure $6 \mathrm{~b}$ shows the impact of ambient wind shear on the normalized area covered by $\mathrm{CC}$ as a function of local 
(a) occurence (\%)

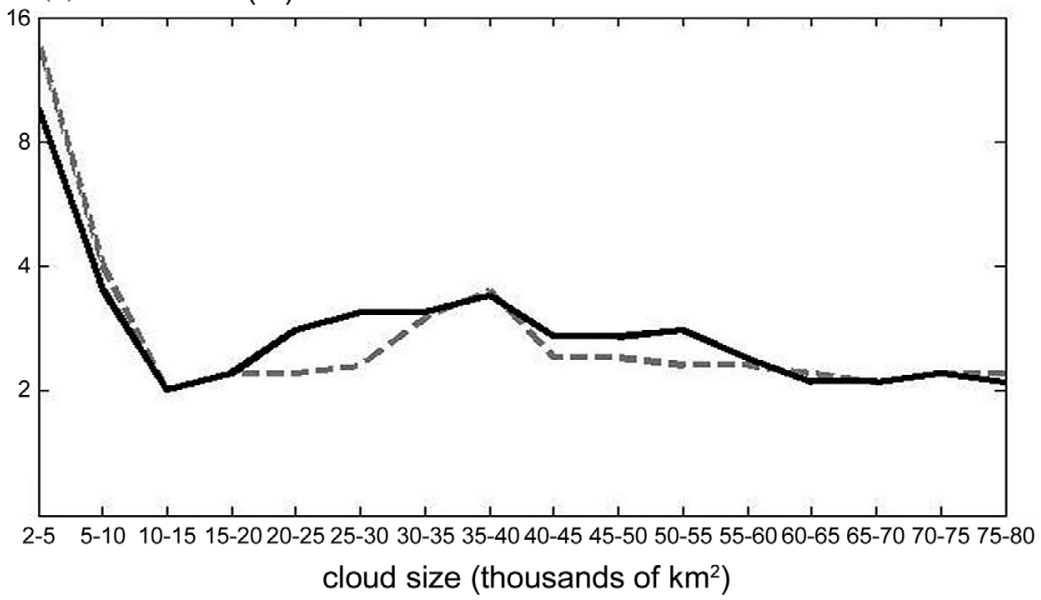

(b) cloud area cover (\%)

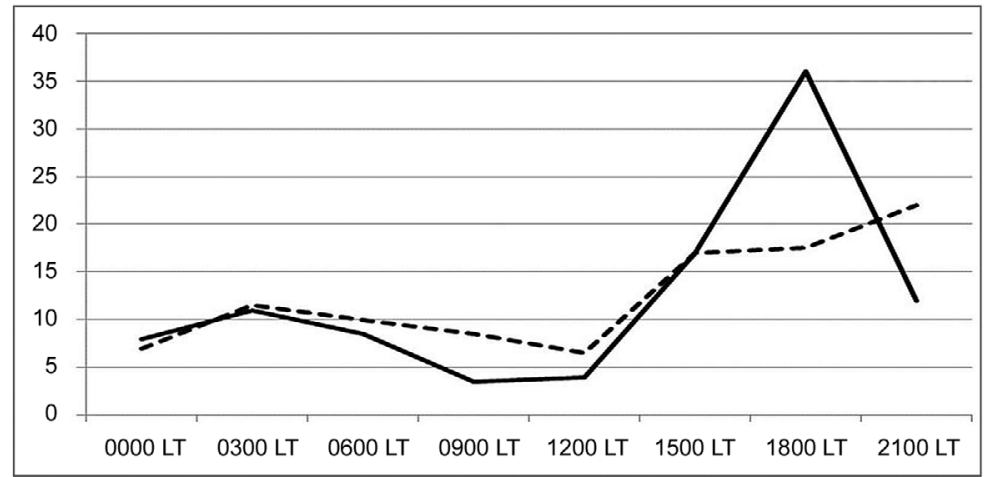

Fig. 6. (a) Frequency distribution of the size of CC during JJA 1999 - 2000 over the region A. Solid and dashed lines represent before and after noon distributions, respectively. The normalization is by the total number of CC in a day (i.e., before and after noon together). The scale in y-axis is logarithmic, which is chosen to highlight differences in two curves. (b) Diurnal cycle of the area covered by all CC normalized by the total area covered in a day in the region A. Dotted and solid lines correspond respectively to area-averaged daily mean zonal wind stronger and weaker than $10 \mathrm{~m} \mathrm{~s}^{-1}$ respectively at $500 \mathrm{hPa}$ over the region A.

time in JJA 1999 - 2000. Normalization was carried out over the total area covered by CC in a day. Using NNRA data, daily mean zonal wind at $500 \mathrm{hPa}$ were averaged over the region A to represent the ambient wind shear $(500 \mathrm{hPa}$ level is above the mountains). Zonal wind was chosen as the meridional component of wind was small. Daily means were taken because the diurnal variation of zonal wind is weak. A simple criterion was set: if the zonal wind is equal to or greater than $10 \mathrm{~m} \mathrm{~s}^{-1}$, strong wind shear with respect to the ground is said to exist; the converse denotes weak wind shear. Days with weak and strong shear made up 56\% and 44\% of all days in JJA 1999 - 2000 respectively. The phase of the diurnal cycle is similar under strong and weak wind shear. But the diurnal variation is much stronger under weak wind shear. Thus, weak mid-tropospheric wind tends to favor the occurrence of afternoon $\mathrm{CC}$ which are mostly of a size less than $10000 \mathrm{~km}^{2}$, i.e., at the mesoscale (Fig. 6a). Bartels and Maddox (1991) suggested that the development of MCSs via the formation of mesovortices is helped by weak vertical shear and weak flow at midlevel.

\subsubsection{Life Cycle of Cloud Clusters}

The lifetime of a TC is defined as the time of the last appearance minus the time of the first appearance of that TC. The temporal resolution of our METEOSAT-5 dataset causes the lifetime of a TC to be quantified in 3 hourly intervals. Figure 7 shows the frequency distribution of lifetimes of TC during JJA 1999 - 2000. In all three regions, most TC live for 3 hours. There was no TC lasting for more than 9 hours. In reality, a cloud cluster may form within 3 hours before the first image that detects it and dissipates within 3 hours after the last image that detects it. So the actual lifetime of cloud clusters could be up to 6 hours longer than the estimates of TC lifetimes. However, this does not detract from the observation that region $\mathrm{C}$ has more $\mathrm{TC}$ that live longer than the other two regions.

Figure 8 shows the times of initiation, attainment of maximum area and dissipation of TC for the three different regions during the summer monsoon. The times of initiation and dissipation were estimated respectively as the 3-hour 
interval just before the first and just after the last satellite image where the TC was detected. The time of attainment of maximum area is taken simply as the time of the satellite image in which the TC has the largest area, with a probable error margin of $\pm 1.5 \mathrm{~h}$. For the Himalayan region, TC form mostly in the early afternoon (1200 - 1500 LT), attain their maximum area around $1500 \mathrm{LT}$ and then dissipate by the early evening (1800 - $2100 \mathrm{LT})$. In region B, initiations tend to occur in the early morning $(0600-0900 \mathrm{LT})$ but maximum area is only attained around noon (1200 LT) followed by dissipation in the early afternoon (1200 - 1500 LT). The region $\mathrm{C}$ stands out among the three regions in that initiation, attainment of maximum area and dissipation all tend to take place before noon (around 0300 - 0600, 0600, and 0900 - 1200 LT respectively). Our study concurred with Zuidema (2003) with regard to the diurnal cycle over region C. The gradual delay in the preferred time of initiation, attainment of maximum area and dissipation northward from region $\mathrm{C}$ through region $\mathrm{B}$ to the region $\mathrm{A}$ is evident. While this is suggestive of a dominant northward migration of cloud clusters from regions C through B to A, Zuidema (2003) and others (e.g., Miyakawa and Satomura 2006) have noted that southward migration is also possible.

\section{TRMM RESULTS}

Ten years of TRMM 3B42 rainfall data (1999 - 2008) was analyzed. The findings have the statistical significance to establish the robustness of the same phenomena that was revealed in the shorter METEOSAT-5 dataset. Our TRMM results are also in agreement with rainfall diurnal cycle as shown by Krishnamurti and Kishtawal (2000).

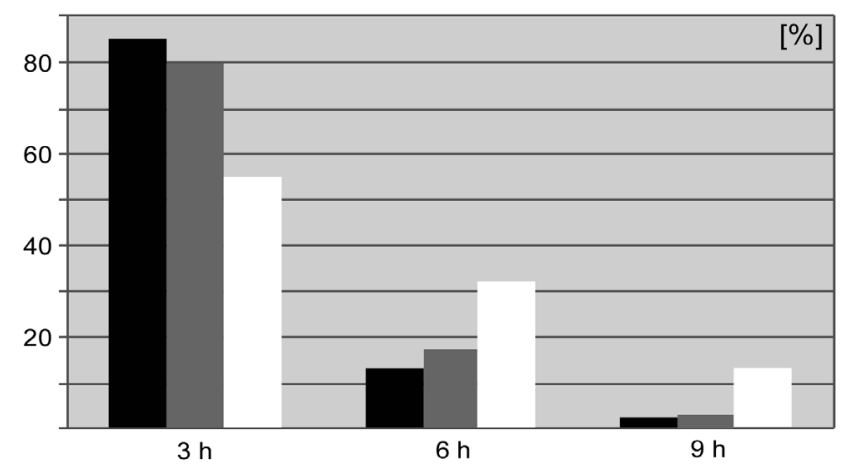

Fig. 7. Frequency distribution of TC over their lifetime in three regions over a day in JJA 1999 - 2000. The black, gray and white bars denote occurrence for the regions $\mathrm{A}, \mathrm{B}$, and $\mathrm{C}$, respectively.
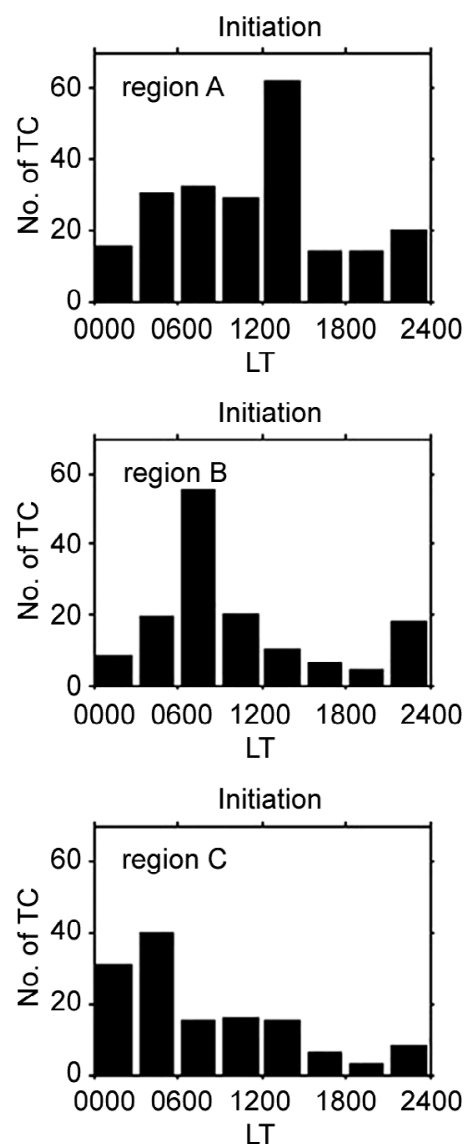
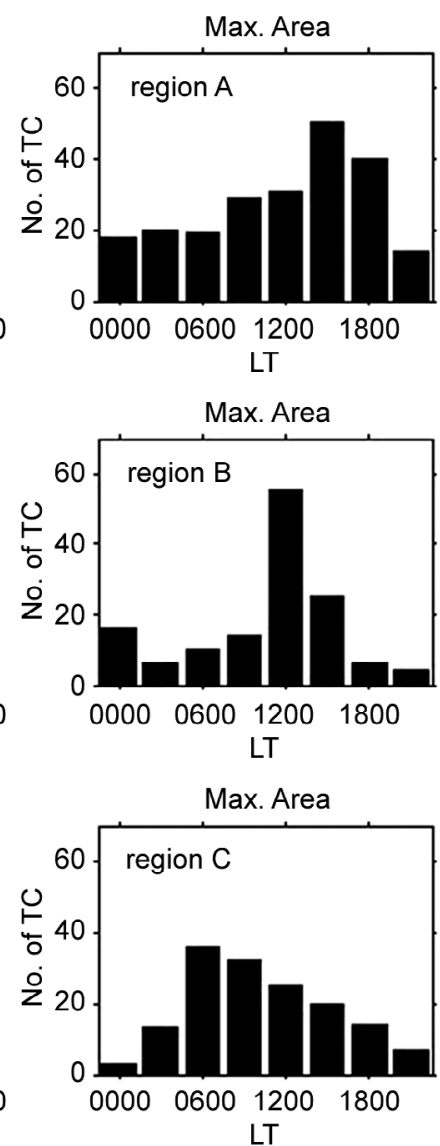
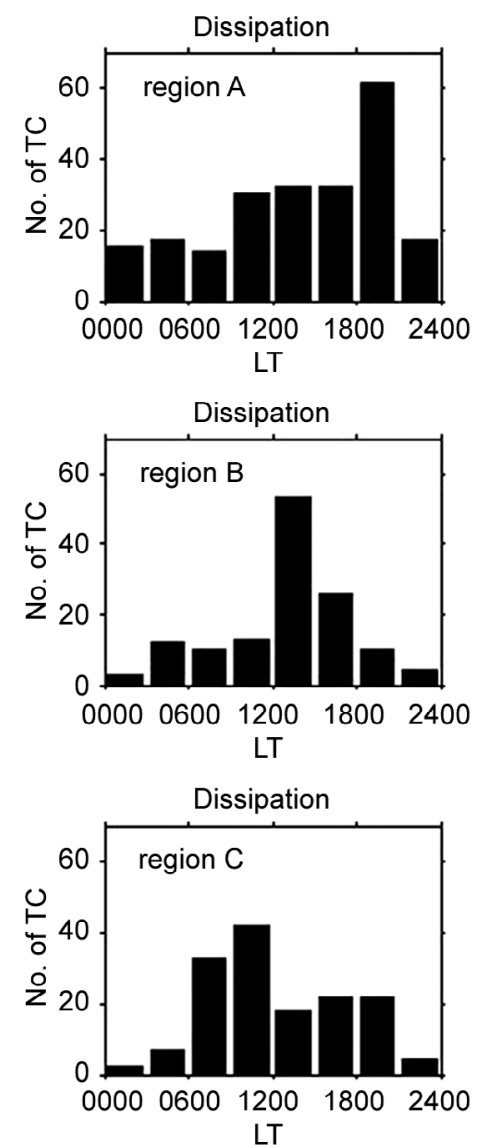

Fig. 8. The number of TC distributed over their local time of initiation (left column), attainment of maximum area (middle column) and dissipation (right column) in JJA 1999 - 2000. The first, second and third rows correspond to the regions A, B, and C respectively. 
The strength of diurnal cycle was investigated using a normalized differential rainfall index (NDRI) as suggested by Yamamoto et al. (2008).

$\mathrm{NDRI}=\frac{R R_{\text {max }}-R R_{\text {mean }}}{R R_{\text {mean }}}$

Here, $R R_{\text {max }}$ is the peak rain rate and $R R_{\text {mean }}$ is the mean rain rate over a day in the climatology. This index shows the prominence of rain at the peak local time compared to the average. NDRI is not a good measure over arid regions as it tends to be large because $R R_{\text {mean }}$ is small. For regions of moderate and heavy rain, NDRI does generally indicate amplitude of diurnal variation.

The spatial distribution of NDRI during MAM and JJA of 1999 - 2008 is shown in Figs. 9a and b, respectively. Moderate to large NDRI over region $\mathrm{C}$ suggests relatively strong diurnal variations. Over regions $\mathrm{A}$ and $\mathrm{B}$, the NDRI values are more variable.

Figure 10 shows the diurnal variations of spatial pattern of averaged rainfall during 1999 - 2008. It is expected that there is more rainfall activity in the summer monsoon than the pre-monsoon season over the sub-continent. Importantly, there is nighttime rainfall in addition to daytime
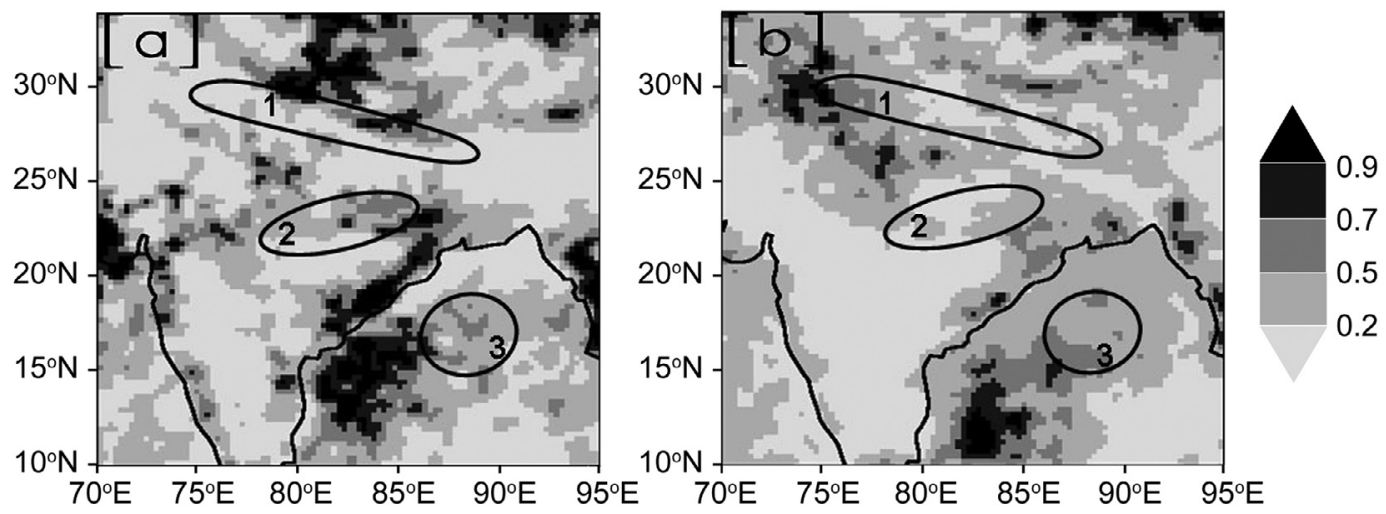

Fig. 9. Normalized Difference Rainfall Index (NDRI) derived from TRMM (3B42) dataset: (a) for MAM 1999 - 2008, and (b) for JJA 1999 - 2008. Regions marked 1 to 3 represent regions A, B, and C respectively.
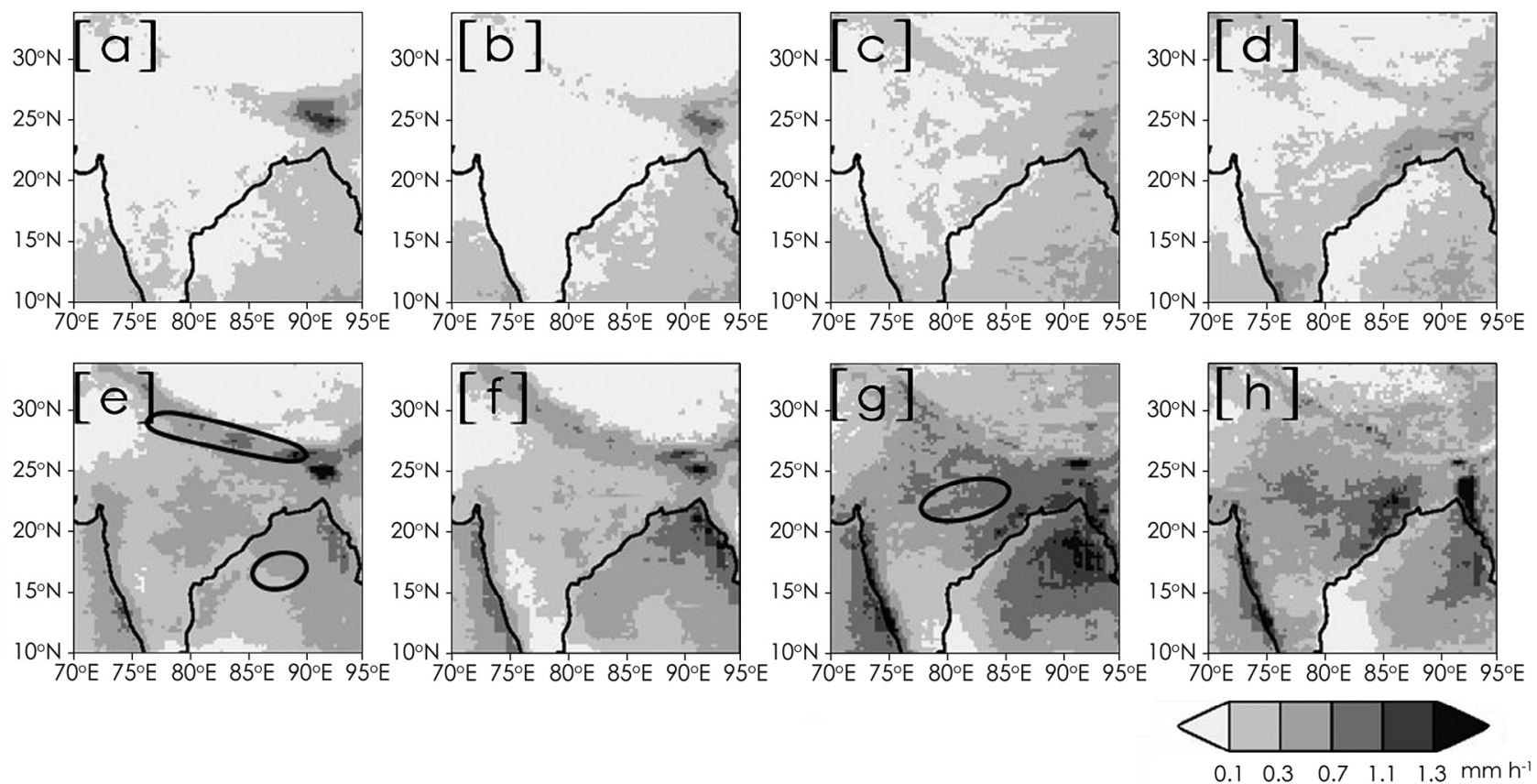

Fig. 10. Spatial distribution of averaged rainfall from TRMM (3B42) dataset: (a), (b), (c), and (d) represent 0300, 0600, 1500, and 1800 LT during MAM 1999 - 2008 respectively and (e), (f), (g) and (h) represent 0300, 0600, 1500, and 1800 LT during JJA 1999 - 2008, respectively. In panel (e), the elongated ellipse highlights enhanced rainfall over the region A while the small ellipse shows the rainfall over region $\mathrm{C}$ starting in the early morning. In panel (g), the ellipse highlights the late afternoon rainfall over region B. 
rainfall during the summer monsoon over region A that is weak during pre-monsoon (cf. Figs. 10a and e). During the pre-monsoon season in region $\mathrm{A}$, the low nighttime rainfall in the TRMM observations does not correspond with the high nighttime occurrence of CC noted earlier. One possible reason may be that while deep clouds occur frequently in the Himalayas during the pre-monsoon, they bring little rain. Such deep but little-precipitating clouds have also been noted in the Indian subcontinent by Zipser et al. (2006). For the summer monsoon season, there is concentration of intense nighttime rainfall over the region $\mathrm{A}$. The nighttime occurrence of CC, which could imply the likelihood of rain, is evident in the METEOSAT-5 data analysis (cf. elongated ellipses in Figs. 10e and 4b). These results are consistent with spatial patterns of the diurnal cycle of precipitation observations in the region (Barros and Lang 2003; Bhatt and Nakamura 2005). The number of CC noted by METEOSAT-5 is lower in nighttime than daytime (cf. Fig. 6a), there is a possibility that nocturnal CC precipitate more than daytime $\mathrm{CC}$ on average.

In region $\mathrm{B}$, summer monsoon is distinguished from pre-monsoon by the characteristic intense afternoon rainfall (cf. the ellipse in Fig. 10g). Our earlier METEOSAT-5 results indicated that this late afternoon rainfall comes mainly from convection of moderate depth rather than deep convection (cf. Figs. $4 \mathrm{f}$ and $5 \mathrm{c}$ ). There is intense rainfall over the region $\mathrm{C}$ during the summer monsoon season with widespread rainfall activity beginning in the early morning and persisting 9 hours or more, just as seen in the METEOSAT-5 results (cf. Fig. 7 and bottom row of Fig. 8).

\section{DISCUSSION}

In-depth examination into plausible explanations for the observations would be helped by data analysis from more observational platforms and by numerical modeling which are beyond the scope of this paper; the aim of this section is to bring out and discuss on possible reasons for the observed diurnal variations.

Over region A, there were many more small (2000 $5000 \mathrm{~km}^{2}$ ) convective systems than big ones (30000 - 50000 $\mathrm{km}^{2}$ ) in the afternoon during the summer monsoon season. Our results agree with those of Hirose and Nakamura (2005) who identified afternoon cumulus scale convective systems in the same season in the Himalayas. Kurosaki and Kimura (2002) also observed predominant low-level clouds over the southern slopes of eastern Himalayas suggestive of smallscale local circulations. In a modeling study by Kuwagata et al. (2001), thermally induced local circulations caused small cloud systems to form during daytime over a valley in the Tibetan Plateau. Thus, it is possible that sensible daytime heating in the boundary layer generates up-valley flows over the southern slopes of the Himalayas in region A. This would tend to set up single-cell circulations between up- wind slopes and valley bottoms. Therefore, convective cells of cumulus scale are likely favored by the multiple ridgevalley topography in region $\mathrm{A}$.

Nighttime convective activity was present over region A during the summer monsoon season, as already noted by some earlier studies (e.g., Barros and Lang 2003; Bhatt and Nakamura 2005; Hirose and Nakamura 2005). This can be explained in the following manner: the surface winds over the southern slopes of the Himalayas switch from upslope during the day to downslope around midnight or early morning (Egger et al. 2000; Barros and Lang 2003). The downslope flow is driven by radiative cooling of air above the elevated terrain. Confluence between the downslope flow and the prevailing southwesterly monsoon flow leads to increased nighttime convective activity (Barros and Lang 2003; Bhatt and Nakamura 2006).

Diurnal variation was noted to be stronger for weak ambient wind shear at $500 \mathrm{hPa}$ over region A during the summer monsoon season. Ambient wind shear over region A is probably related with the location of the subtropical jet. The ECMWF climatology of summer wind distribution at $500 \mathrm{hPa}$ suggests that a subtropical westerly jet lies nearly at the northern edge within region A (not shown). Using NNRA data, Romatschke et al. (2010) suggested that at $500 \mathrm{hPa}$, the jet lies around the high Himalayas (approximately $29^{\circ} \mathrm{N}$ ) during the summer monsoon. Ueno et al. (2008) further noted that there were frequent northward displacement of the subtropical jet in the summers of 1999 and 2000 studied in this paper. Thus, it is possible that the northward shift of the subtropical jet weakens the ambient wind shear in region A and provides favorable conditions for diurnal cloud activity. Using surface observations and NNRA data, Ueno et al. (2008) noted essentially the same phenomenon over the Khumbu region (near Mt. Everest base camp) in the eastern Himalayas.

Over region B, CC analysis demonstrated that deep convection was less frequent in the summer monsoon season, while $\mathrm{CCF}$ analysis revealed that a significant contribution to cloudiness came from convection of moderate depth. Houze et al. (2007) remarked that stratiform rainfall is responsible for most of the monsoon precipitation over South Asia. The stratiform rainfall comes from the long-lived decaying phase of convection that is associated with monsoon depressions originating in the BOB. Radar echoes of this stratiform rainfall are small in horizontal extent and not very tall (Houze et al. 2007) and so are consistent with the convection of moderate depth that is detected in this work.

In the pre-monsoon season, deep convection occurs with the highest frequency over region B as revealed from our CC analysis. Kodama et al. (2005) reported maximum lightning activity (a proxy of deep convection) over north India including region B. Romatschke et al. (2010) also reported high probability of radar rain echo occurrence in the same domain. The enhanced deep convection there is most 
probably due to the dry-line over north India as noted in Weston (1972). He suggested that dry warm continental air caps the low-level moist air and this juxtaposition favors convection. Yamane and Hayashi (2006) also suggested that the large static instability and vertical wind shear over the South Asian dry-line region help force thunderstorms. It is suggested that dry-line convective processes take place in the afternoon leading to deep convective development over region $\mathrm{B}$.

During the summer monsoon season, morning maximum in convective activity was observed over region $\mathrm{C}$. This morning maximum is similar to that previously noted by Ohsawa et al. (2001), Zuidema (2003), Hirose and Nakamura (2005), and Yamamoto et al. (2008). The morning land breeze reinforced by the synoptic southwesterly flow over India probably moves convection offshore from eastern coast of India to the BOB. In the BOB, convergence of the land breeze with the southeasterly monsoon flow further enhanced convection, as speculated by Zuidema (2003).

Over region $\mathrm{C}$, more $\mathrm{TC}$ survived beyond 3 hours in the summer monsoon season. Long-lived TC over the BOB region has already been noted by Zuidema (2003) before. In nearby Bangladesh, analysis by Rafiuddin et al. (2010) also found more long-lived ( $>3 \mathrm{~h}$ ) MCSs. Thus, there seems at least some similarity between the observed lifetimes of $\mathrm{TC}$ between the $\mathrm{BOB}$ and Bangladesh and so the reason behind long-lived $\mathrm{TC}$ in region $\mathrm{C}$ is unlikely unique to the sea surface boundary condition per se. While the real reason remains elusive, it is speculated from mesoscale dynamics theory (Houze 1993) that southerly monsoon flow from the BOB into Bangladesh may provide the appropriate low-level wind shear to organize and sustain long-lived mesoscale convection in region $\mathrm{C}$.

A gradual delay in the preferred time of initiation, attainment of maximum area and dissipation of TC northward from region $\mathrm{C}$ through region $\mathrm{B}$ to region $\mathrm{A}$ was noted. Whether this delay is representative of a progression through the entire South Asia domain and if so, what causes it, are unclear at this time.

\section{SUMMARY}

The climatological features of the diurnal cycle and spatial variability of cloudiness were investigated over South Asia using data from the METEOSAT-5 during March - May and June - August of 1999 and 2000. Analysis of ten years of TRMM rainfall product (3B42) was performed to enhance the confidence in 2-year METEOSAT-5 results. Two methods were used to detect cloudiness: one method counted cloud clusters (CC) and utilized cloud tracking technique to identify "time clusters" (TC); and the other method computed cloud cover frequency (CCF). CC was defined as a contiguous area of pixels with $\mathrm{T}_{\mathrm{BB}}$ lower than the threshold of $219 \mathrm{~K}$. The CCF was derived using
$235 \mathrm{~K}$ as the threshold.

Three convective centers of interest were investigated: region $\mathrm{A}$ in the Himalayas; region $\mathrm{B}$ in north India and region $\mathrm{C}$ in the Bay of Bengal (BOB). For pre-monsoon season, the preferred region of occurrence of $\mathrm{CC}$ was over region $\mathrm{B}$. In the pre-monsoon season, there are many $\mathrm{CC}$ over region $B$ and region $A$ in the mid-afternoon (1500 LT). In the summer monsoon season, the peak occurrence of $\mathrm{CC}$ appears around $1200 \mathrm{LT}$ over the region B and still around 1500 LT over the region A. For region C, CC is most numerous around $0600 \mathrm{LT}$ in both seasons, showing clear contrast with the other two land regions.

The life cycle of cloud clusters during summer monsoon is worthy of note. Statistically speaking, there is a gradual delay in the preferred time of initiation, attainment of maximum area and dissipation as one progresses northward from regions $\mathrm{C}$ through $\mathrm{B}$ to $\mathrm{A}$. More clusters survive for longer than 3 hours in region $\mathrm{C}$ as compared to the other two regions.

Analysis of TRMM data generally confirmed the diurnal variations in METEOSAT-5 data. There is good agreement between the space-time variability of cloudiness and rainfall with only one exception: the morning peak in cloudiness in region A during the pre-monsoon season is associated with little rain.

The underlying forcing mechanisms are expected to differ over the three regions and have been discussed in the last section. Over region A, sensible heating can account for daytime convective activity while radiative cooling could be triggering the nighttime convective activity. Convective activity over region $\mathrm{B}$ can be explained by the dry-line mechanism which in essence is the capping of low-level moist air by warm dry continental air. The convergence of the land breeze with the southeasterly monsoon flow is a likely reason for convective activity over the region $\mathrm{C}$.

The observational analyses such as presented here cannot actually unravel the mechanisms of mesoscale processes. Higher spatial and temporal resolution meteorological data would be required to evaluate these mechanisms. The 2-year period is not long enough for robust data statistics and demands further study of METEOSAT-5 data to verify the results.

Acknowledgements The authors would like to acknowledge the anonymous reviewers for their useful comments that resulted in a better paper. This research was conducted when the first author was in the Laboratory of Satellite Meteorology of the Hydrospheric Atmospheric Research Center, Japan.

\section{REFERENCES}

Adler, R. F., G. J. Huffman, D. T. Bolvin, S. Curtis, and E. J. Nelkin, 2000: Tropical rainfall distributions deter- 
mined using TRMM combined with other satellite and rain gauge information. J. Appl. Meteorol., 39, 20072023, doi: 10.1175/1520-0450(2001)040<2007:TRDD UT>2.0.CO;2. [Link]

Anyamba, A., C. J. Tucker, and R. Mahoney, 2002: From El Niño to La Niña: Vegetation response patterns over east and southern Africa during the 1997-2000 period. J. Climate, 15, 3096-3103, doi: 10.1175/1520-0442(20 02)015<3096:FENOTL >2.0.CO;2. [Link]

Arkin, P. A. and B. N. Meisner, 1987: The relationship between large-scale convective rainfall and cold cloud over the western hemisphere during 1982-84. Mon. Weather Rev., 115, 51-74, doi: 10.1175/1520-0493(19 87) $115<0051$ :TRBLSC $>2.0 . \mathrm{CO}$;2. [Link]

Barros, A. P. and T. J. Lang, 2003: Monitoring the monsoon in the Himalayas: Observations in central Nepal, June 2001. Mon. Weather Rev., 131, 1408-1427, doi: 10.11 75/1520-0493(2003)131<1408:MTMITH>2.0.CO;2. [Link]

Bartels, D. L. and R. A. Maddox, 1991: Midlevel cyclonic vortices generated by mesoseale convective systems. Mon. Weather Rev., 119, 104-118, doi: 10.1175/15200493(1991)119<0104:MCVGBM>2.0.CO;2. [Link]

Bhatt, B. C. and K. Nakamura, 2005: Characteristics of monsoon rainfall around the Himalayas revealed by TRMM Precipitation Radar. Mon. Weather Rev., 133, 149-165, doi: 10.1175/MWR-2846.1. [Link]

Bhatt, B. C. and K. Nakamura, 2006: A climatological-dynamical analysis associated with precipitation around the southern part of the Himalayas. J. Geophys. Res., 111, D02115, doi: 10.1029/2005JD006197. [Link]

Carbone, R. E., J. D. Tuttle, D. A. Ahijevych, and S. B. Trier, 2002: Inferences of predictability associated with warm season precipitation episodes. J. Atmos. Sci., 59, 2033-2056, doi: 10.1175/1520-0469(2002)059<2033: IOPAWW>2.0.CO;2. [Link]

Egger, J., S. Bajrachaya, U. Egger, R. Heinrich, J. Reuder, P. Shakya, H. Wendt, and V. Wirth, 2000: Diurnal winds in the Himalayan Kali Gandaki Valley. Part I: Observations. Mon. Weather Rev., 128, 1106-1122, doi: 10.1 175/1520-0493(2000)128<1106:DWITHK>2.0.CO;2. [Link]

Fritsch, J. M., R. J. Kane, and C. R. Chelius, 1986: The contribution of mesoscale convective weather systems to the warm-season precipitation in the United States. J. Clim. Appl. Meteorol., 25, 1333-1345, doi: 10.117 5/1520-0450(1986)025<1333:TCOMCW>2.0.CO;2. [Link]

Fu, Y., F. Jingyi, Z. Hongfang, L. Rui, and L. Dong, 2006: Precipitation structures of a thermal convective system happened in the central western subtropical Pacific anticyclone. Acta Meteorol. Sin., 20, 232-243.

Gambheer, A. V. and G. S. Bhat, 2001: Diurnal variation of deep cloud systems over the Indian region using IN-
SAT-1B pixel data. Meteorol. Atmos. Phys., 78, 215225, doi: 10.1007/s703-001-8175-4. [Link]

Goswami, B. N., 2000: Comments on 'Choice of South Asian summer monsoon indices.' Bull. Amer. Meteorol. Soc., 81, 821-822, doi: 10.1175/1520-0477(2000) 081<0821:CAA >2.3.CO;2. [Link]

Hilgendorf, E. R. and R. H. Johnson, 1998: A study of the evolution of Mesoscale Convective Systems using WSR-88D data. Weather Forecast., 13, 437-452, doi: 10.1175/1520-0434(1998)013<0437:ASOTEO>2.0. $\mathrm{CO} ; 2$. [Link]

Hirose, M. and K. Nakamura, 2005: Spatial and diurnal variation of precipitation systems over Asia observed by the TRMM precipitation radar. J. Geophys. Res., 110, D05106, doi: 10.1029/2004JD004815. [Link]

Houze, R. A. Jr., 1993: Cloud Dynamics, Academic Press, San Diego.

Houze, R. A. Jr. and D. D. Churchill, 1987: Mesoscale organization and cloud microphysics in a Bay of Bengal depression. J. Atmos. Sci., 44, 1845-1868, doi: 10.11 75/1520-0469(1987)044<1845:MOACMI>2.0.CO;2. [Link]

Houze, R. A. Jr., D. C. Wilton, and B. F. Smull, 2007: Monsoon convection in the Himalayan region as seen by the TRMM precipitation radar. Q. J. R. Meteorol. Soc., 133, 1389-1411, doi: 10.1002/qj.106. [Link]

Huffman, G. J., D. T. Bolvin, E. J. Nelkin, D. B. Wolff, R. F. Adler, G. Gu, Y. Hong, K. P. Bowman, and E. F. Stocker, 2007: The TRMM multisatellite precipitation analysis (TMPA): Quasi-global, multiyear, combinedsensor precipitation estimates at fine scale. J. Hydrometeorol., 8, 38-55, doi: 10.1175/JHM560.1. [Link]

Johnson, R. H., 2009: Diurnal cycle of monsoon convection. In: Chang, C. P., B. Wang, and N. C. G. Lau (Eds.), The Global Monsoon System: Research and Forecast, $2^{\text {nd }}$ Ed., World Scientific Publication Co., Singapore.

Kanamitsu, M., W. Ebisuzaki, J. Woollen, S. K. Yang, J. J. Hnilo, M. Fiorino, and G. L. Potter, 2002: NCEPDOE AMIP-II Reanalysis (R-2). Bull. Amer. Meteorol. Soc., 83, 1631-1643, doi: 10.1175/BAMS-83-11-1631. [Link]

Kodama, Y. M., A. Ohta, M. Katsumata, S. Mori, S. Satoh, and H. Ueda, 2005: Seasonal transition of predominant precipitation type and lightning activity over tropical monsoon areas derived from TRMM observations. Geophys. Res. Lett., 32, L14710, doi: 10.1029/2005GL022986. [Link]

Kondo, Y., A. Higuchi, and K. Nakamura, 2006: Smallscale cloud activity over the Maritime Continent and the Western Pacific as revealed by satellite data. Mon. Weather Rev., 134, 1581-1599, doi: 10.1175/MWR31 32.1. [Link]

Krishnamurti, T. N. and C. M. Kishtawal, 2000: A pronounced continental-scale diurnal mode of the Asian 
summer monsoon. Mon. Weather Rev., 128, 462-473, doi: 10.1175/1520-0493(2000)128<0462:APCSDM> 2.0.CO;2. [Link]

Kurosaki, Y. and F. Kimura, 2002: Relationship between topography and daytime cloud activity around Tibetan Plateau. J. Meteorol. Soc. Jpn., 80, 1339-1355, doi: 10.2151/jmsj.80.1339. [Link]

Kuwagata, T., A. Numaguti, and N. Endo, 2001: Diurnal variation of water vapor over the central Tibetan Plateau during summer. J. Meteorol. Soc. Jpn., 79, 401418, doi: 10.2151/jmsj.79.401. [Link]

Laing, A. G. and J. M. Fritsch, 1997: The global population of mesoscale convective complexes. Q. J. R. Meteorol. Soc., 123, 389-405, doi: 10.1002/qj.49712353807. [Link]

Lang, T. J. and A. P. Barros, 2002: An investigation of the onsets of the 1999 and 2000 monsoons in central Nepal. Mon. Weather Rev., 130, 1299-1316, doi: 10.11 75/1520-0493(2002)130<1299:AIOTOO>2.0.CO;2. [Link]

Lensky, I. M. and D. Rosenfeld, 1997: Estimation of precipitation area and rain intensity based on the microphysical properties retrieved from NOAA AVHRR data. $J$. Appl. Meteorol., 36, 234-242, doi: 10.1175/1520-0450 (1997)036<0234:EOPAAR>2.0.CO;2. [Link]

Liu, C., M. W. Moncrieff, and J. D. Tuttle, 2008: A note on propagating rainfall episodes over the Bay of Bengal. Q. J. R. Meteorol. Soc., 134, 787-792, doi: 10.1002/ qj.246. [Link]

Machado, L. A. T., W. B. Rossow, R. L. Guedes, and A. W. Walker, 1998: Life cycle variations of mesoscale convective systems over the Americas. Mon. Weather Rev., 126, 1630-1654, doi: 10.1175/1520-0493(1998) 126<1630:LCVOMC > 2.0.CO;2. [Link]

Mapes, B. E. and R. A. Houze Jr., 1993: Cloud clusters and superclusters over the oceanic warm pool. Mon. Weather Rev., 121, 1398-1416, doi: 10.1175/1520-04 93(1993)121<1398:CCASOT>2.0.CO;2. [Link]

Minoura, D., R. Kawamura, and T. Matsuura, 2003: A mechanism of the onset of the south Asian summer monsoon. J. Meteorol. Soc. Jpn., 81, 563-580, doi: 10.2151/jmsj.81.563. [Link]

Miyakawa, T. and T. Satomura, 2006: Seasonal variation and environmental properties of southward propagating mesoscale convective systems over the Bay of Bengal. SOLA, 2, 88-91, doi: 10.2151/sola.2006-023. [Link]

Nesbitt, S. W. and E. J. Zipser, 2003: The diurnal cycle of rainfall and convective intensity according to three years of TRMM measurements. J. Climate, 16, 14561475.

Ohsawa, T., H. Ueda, T. Hayashi, A. Watanabe, and J. Matsumoto, 2001: Diurnal variations of convective activity and rainfall in tropical Asia. J. Meteorol. Soc. Jpn.,
79, 333-352, doi: 10.2151/jmsj.79.333. [Link]

Rafiuddin, M., H. Uyeda, and M. N. Islam, 2010: Characteristics of monsoon precipitation systems in and around Bangladesh. Int. J. Climatol., 30, 1042-1055, doi: 10. 1002/joc.1949. [Link]

Rahman, S. and B. Simon, 2006: Summer monsoon intraseasonal oscillation over eastern Arabian Sea - As revealed by TRMM microwave imager products. J. Earth Syst. Sci., 115, 575-586, doi: 10.1007/BF02702910. [Link]

Roca, R., M. Viollier, L. Picon, and M. Desbois, 2002: A multisatellite analysis of deep convection and its moist environment over the Indian Ocean during the winter monsoon. J. Geophys. Res., 107, 8012, doi: 10.1029/2000JD000040. [Link]

Romatschke, U., S. Medina, and R. A. Houze Jr., 2010: Regional, seasonal and diurnal variations of extreme convection in the South Asian region. J. Climate, 23, 419-439, doi: 10.1175/2009JCLI3140.1. [Link]

Roy, S. S. and R. C. Balling Jr., 2006: Diurnal variations in summer season precipitation in India. Int. J. Climatol., 27, 969-976, doi: 10.1002/joc.1458. [Link]

Short, D. A. and J. M. Wallace, 1980: Satellite-inferred morning-to-evening cloudiness changes. Mon. Weather Rev., 108, 1160-1169, doi: 10.1175/1520-0493(19 80) $108<1160$ :SIMTEC $>2.0 . C O ; 2$. [Link]

Shreatha, M. L., 2000: Interannual variation of summer monsoon rainfall over Nepal and its relation to southern oscillation index. Meteorol. Atmos. Phys., 75, 21 28, doi: 10.1007/s007030070012. [Link]

Ueno, K., R. B. Kayastha, M. R. Chitrakar, O. R. Bajracharya, A. P. Pokhrel, H. Fujinami, T. Kadota, H. Iida, D. P. Manandhar, M. Hattori, T. Yasunari, and M. Nakawo, 2001: Meteorological observations during 19942000 at the automatic weather station (GEN-AWS) in Khumbu region, Nepal Himalayas. Bull. Glaciol. Res., 18, 23-30.

Ueno, K., K. Toyotsu, L. Bertolani, and G. Tartari, 2008: Stepwise onset of monsoon weather observed in the Nepal Himalaya. Mon. Weather Rev., 136, 2507-2522, doi: 10.1175/2007MWR2298.1. [Link]

Uppala, S. M., P. W. KÅllberg, A. J. Simmons, U. Andrae, V. Da Costa Bechtold, M. Fiorino, J. K. Gibson, J. Haseler, A. Hernandez, G. A. Kelly, X. Li, K. Onogi, S. Saarinen, N. Sokka, R. P. Allan, E. Andersson, K. Arpe, M. A. Balmaseda, A. C. M. Beljaars, L. Van De Berg, J. Bidlot, N. Bormann, S. Caires, F. Chevallier, A. Dethof, M. Dragosavac, M. Fisher, M. Fuentes, S. Hagemann, E. Hólm, B. J. Hoskins, L. Isaksen, P. A. E. M. Janssen, R. Jenne, A. P. McNally, J.-F. Mahfouf, J.J. Morcrette, N. A. Rayner, R. W. Saunders, P. Simon, A. Sterl, K. E. Trenberth, A. Untch, D. Vasiljevic, P. Viterbo, and J. Woollen, 2005: The ERA-40 re-analysis. Q. J. R. Meteorol. Soc., 131, 2961-3012, doi: 10.1256/qj.04.176. [Link] 
Wallace, J., 1975: Diurnal variations in precipitation and thunderstorm frequency over the conterminous United States. Mon. Weather Rev., 103, 406-419.

Wang, C. C., G. T.-J. Chen, and R. E. Carbone, 2004: A climatology of warm-season cloud patterns over East Asia based on GMS infrared brightness temperature observations. Mon. Weather Rev., 132, 1606-1629, doi: 10.1175/1520-0493(2004)132<1606: ACOWCP>2.0. $\mathrm{CO} ; 2$. [Link]

Webster, P. J. and S. Yang, 1992: Monsoon and ENSO: Selectively interactive systems. Q. J. R. Meteorol. Soc., 118, 877-926, doi: 10.1256/smsqj.50704. [Link]

Webster, P. J., E. F. Bradley, C. W. Fairall, J. S. Godfrey, P. Hacker, R. A. Houze Jr., R. Lukas, Y. Serra, J. M. Hummon, T. D. M. Lawrence, C. A. Russell, M. N. Ryan, K. Sahami, and P. Zuidema, 2002: The joint airsea monsoon interaction experiment (jasmine) pilot study. Bull. Amer. Meteorol. Soc., 83, 1603-1630, doi: 10.1175/BAMS-83-11-1603. [Link]

Weston, K. J., 1972: The dry-line of Northern India and its role in cumulonimbus convection. Q.J. R. Meteorol. Soc., 98, 519-531, doi: 10.1002/qj.49709841704. [Link]

Williams, M. and R. A. Houze Jr., 1987: Satellite-observed characteristics of winter monsoon cloud clusters. Mon. Weather Rev., 115, 505-519, doi: 10.1175/1520-0493 (1987)115<0505:SOCOWM>2.0.CO;2. [Link]

Xie, S. P., H. Xu, N. H. Saji, and Y. Wang, 2006: Role of narrow mountains in large-scale organization of Asian monsoon convection. J. Climate, 19, 3420-3429, doi: 10.1175/JCLI3777.1. [Link]

Yamamoto, M. K., F. A. Furuzawa, A. Higuchi, and K. Nakamura, 2008: Comparison of diurnal variations in precipitation systems observed by TRMM PR, TMI, and VIRS. J. Climate, 21, 4011-4028, doi: 10.1175/2007JCLI2079.1. [Link]

Yamane, Y. and T. Hayashi, 2006: Evaluation of environmental conditions for the formation of severe local storms across the Indian subcontinent. Geophys. Res. Lett., 33, L17806, doi: 10.1029/2006GL026823. [Link]

Yang, S. and E. A. Smith, 2006: Mechanisms for diurnal variability of global tropical rainfall observed from TRMM. J. Climate, 19, 5190-5226, doi: 10.1175/JCLI 3883.1. [Link]

Yu, R., T. Zhou, A. Xiong, Y. Zhu, and J. Li, 2007: Diurnal variations of summer precipitation over contiguous China. Geophys. Res. Lett., 34, L01704, doi: 10.1029/2006GL028129. [Link]

Zipser, E. J., C. Liu, D. J. Cecil, S. W. Nesbitt, and D. P. Yorty, 2006: Where are the most intense thunderstorms on Earth? Bull. Amer. Meteorol. Soc., 87, 1057-1071, doi: 10.1175/BAMS-87-8-1057. [Link]

Zuidema, P., 2003: Convective clouds over the Bay of Bengal. Mon. Weather Rev., 131, 780-798, doi: 10.1175/15 20-0493(2003)131<0780:CCOTBO>2.0.CO;2. [Link] 